\title{
Pengaruh Fasilitas Kerja Terhadap Kinerja Pegawai Kantor Perusahaan Daerah
}

\author{
${ }^{1}$ Raimon Sya'ban, ${ }^{2}$ Cut Meutia Mustika Suri, ${ }^{3}$ Aulia Akbar, ${ }^{4}$ Irham Khalid \\ ${ }^{1-4}$ Program magister manajemen, Fakultas Ekonomi, Universitas Islam Sumatera Utara
}

Article history

Received: 12 Jan 2021

Revised: 20 Feb 2021

Accepted: 08 Mar 2021

*Corresponding Author: Raimon Sya'ban, Program Studi Magister Manajemen, Fakultas Ekonomi,

Universitas Islam Sumatera Utara

Email:

raimonsyaban@gmail.com

\begin{abstract}
Abstrak: Penelitian ini bertujuan untuk mengetahui pengaruh baik secara bersama-sama maupun parsial antara fasilitas kerja terhadap kinerja pegawai di Kantor Perusahaan Daerah Pasar Kota Medan. Penelitian ini menggunakan metode kuantitatif dengan jenis penelitian penjelasan (explanatory research) dengan menggunakan data primer dan data sekunder. Populasi dalam penelitian ini adalah karyawan di Kantor Perusahaan Daerah Pasar Kota Medan dan sebanyak 82 orang pegawai dijadikan sampel penelitian. Adapun teknik analisis data yang digunakan adalah regresi linear berganda dan parsial dengan menggunakan SPSS 24.0. Hasil analisis regresi menunjukkan bahwa variabel independen yang dimasukkan kedalam model regresi . Variabel fasilitas kerja yang memiliki nilai signifikan pada 0,016. Sehingga dapat disimpulkan bahwa fasilitas kerja berpengaruh terhadap kinerja pegawai (hipotesis 3 diterima). Berdasarkan uji t Variabel fasilitas kerja memiliki nilai p-value (pada kolom Sig.) $0,016<0,05$ artinya signifikan, sedangkan t hitung 2,458 > dari t tabel 1,991 artinya signifikan. Hal ini berarti bahwa fasilitas kerja berpengaruh terhadap kinerja pegawai.
\end{abstract}

Kata Kunci : Pengaruh, Fasilitas Kerja, Kinerja Pegawai Daerah

\section{PENDAHULUAN}

Sebelumnya Rivai (2009) menyatakan bahwa organisasi yang ingin berumur panjang dan sustainable, harus menempatkan SDM yang handal sebagai human capital. Pembinaan SDM organisasi harus diprioritaskan untuk meningkatkan kinerja, mengembangkan budaya koorporasi yang mendukung penerapan inovasi dan fleksibiltas. Pentingnya Peranan Sumber Daya Manusia dalam mewujudkan keselarasan visi dan misi organisasi perlu diimbangi dengan kemampuan organisasi dalam menetapkan nilai - nilai yang mengarah pada tingginya tingkat kenyamanan pegawai terhadap organisasi. Masalah Sumber Daya Manusia secara histeris dapat ditinjau dari perkembangannya sejak dulu. Bahkan masalah Sumber Daya Manusia yang kelihatannya hanya masalah intern dari suatu organisasi, sesungguhnya mempunyai hubungan yang sangat erat dengan peri kehidupan manusia dan masyarakat.

Penelitian tentang peningkatan kinerja telah banyak dilakukan. Berdasarkan penelusuran studi empiris dari Thomas (2010) bahwa faktor yang mempengaruhi kinerja juga adalah fasilitas kerja. Meskipun fasilitas kerja hanya sebagian kecil dari faktor - faktor yang mempengaruhi kinerja, namun keberadaannya tidak dapat diabaikan begitu saja sebab tanpa adanya fasilitas kerja, kegiatan organisasi tidak akan terlaksana dengan baik sesuai dengan tujuan yang diharapkan. Fasilitas kerja sangat dibutuhkan dalam kegiatan organisasi secara formal yang pada umumnya berlangsung disuatu organisasi. Menurut Nitisemito (2009:88) mengemukakan bahwa fasilitas kerja merupakan kelengkapan kerja yang harus dimiliki oleh organisai. pegawai yang akan meningkatkan efisiensi dan efektivitasnya dalam bekerja.

Perusahaan Daerah Pasar Kota Medan bertujuan utuk lebih meningkatkan pertumbuhan ekonomi dan pendapatan asli daerah (PAD) serta meningkatkan pelaksanaan pembangunan di kota Medan. Sesuai dengan fungsinya, maka Perusahaan Daerah Pasar Kota Medan juga dikatakan sebagai fasilitas pasar bagi masyarakat, menyelenggarakan kemanfaatan, pelayanan 
umum dan penyediaan jasa. Hal ini dapat tercapai apabila kedisiplinan tiap individu serta motivasinya dalam bekerja dengan adanya fasilitas kerja yang memadai dapat diharapkan meningkatkan kinerja pegawai lebih optimal.

\section{Landasan Teori}

\section{Kinerja}

Untuk mencapai keberhasilan suatu organisasi dalam mencapai tujuan tergantung pada bagaimana para personel dalam melaksanakan pekerjaaannya sesuai dngan tugas dan tanggung jawabnya masing-masing (Cascio, 2006). Dalam organisasi intansi berhasil tidaknya tujuan instansi sangat ditentukan oleh kinerja pegawai. Karena tugas pegawai adalah mengelola kegiatan bekerja. Berkenaan dengan kinerja pegawai sebagai pehawai, mencakup aspek kemampuan personal, kemampuan profesional dan kemampuan sosial.

\section{Faktor-Faktor Yang Mempengaruhi Kinerja}

Robbins (2009:66) menjelaskan bahwa kinerja pegawai dalam suatu organisasi dipengaruhi oleh tiga faktor yaitu :

1) Faktor Individu

2) Faktor Organisasi

3) Faktor Lingkungan

Faktor lain yang dapat meningkatkan kinerja adalah fasilitas kerja. Dimana fasilitas/sarana adalah alat yang diperlukan untuk menggerakkan kegiatan manajemen dalam rangka mencapai tujuan organisasi. Fasilitas kerja merupakan faktor-faktor yang tidak dapat dipisahkan dari dunia kerja dan merupakan hal yang vital bagi pegawai untuk menyelesaikan tugas-tugasnya. Faktor fasilitas kerja yang lengkap merupakan hal yang penting dan memiliki keterkaitan yang erat dengan kinerja pegawai. Maka apabila perpaduan antara keduanya dapat terpenuhi dengan baik nantinya diharapakn dapat menciptakan suatu iklim kerja yang kondusif sehingga dapat bersinergi dalam rangka meningkatkan kinerja.

\section{METODE PENELITIAN}

Pengumpulan data dalam penelitian menggunakan metode kuantitatif. Dimana semua data diklarifikasi dalam kategori tertentu dengan menggunakan tabel-tabel tertentu, untuk mempermudah dalam menganalisa dengan menggunakan program SPSS for window vs 22.00. Adapun lokasi penelitian yang dilakukan adalah di Perusahaan Daerah Pasar Kota Medan, yang beralamat di Jalan Razak Baru No. 1-A Pasar Petisah Lantai III Medan. Objek penelitian ini adalah pegawai kantor perusahaan daerah Pasar Kota Medan, dengan variabel yang diteliti yaitu disiplin Variabel $\mathrm{X}_{1}$, motivasi variabel $\mathrm{X}_{2}$, fasilitas kerja $\mathrm{X}_{3}$, dan kinerja variabel Y. Populasi dalam penelitian ini adalah seluruh karyawan yang ada pada bagian operasional perusahaan Daerah Pasar Kota Medan yang berjumlah 465 orang. Untuk menentukan jumlah sampel, digunakan Pendapat Slovin dalam sekaran dan Bougic (2010:112) dengan menggunakan formula sebagai berikut:

$$
n \quad=\frac{N}{1+N e^{2}}
$$

Keterangan :

$\mathrm{n} \quad=$ Jumlah sampel 
$\mathrm{N} \quad=$ Jumlah Populasi

e $\quad=$ Kesalahan yang ditolerir dalam penarikan sampel yaitu $10 \%$

Teknik pengumpulan data dengan cara memberikan kuesioner atau angket penelitian kepada 88 orang pegawai kantor perusahaan daerah Pasar Kota Medan, dengan berpedoman pada Skala Likert.

\section{Pengujian Kualitas Data}

\section{Uji Validitas}

1. $r_{\text {hitung }}>r_{\text {tabel }}$, maka instrumen yang digunakan dinyatakan valid

2. $\mathrm{r}_{\text {hitung }}<\mathrm{r}_{\text {tabel}}$, maka instrumen yang digunakan dinyatakan tidak valid

\section{Uji Reliabilitas}

a.Repeated Measure atau pengukuran ulang

b. One shot atau pengukuran sekali saja.

\section{Pengujian Hipotesis}

Untuk menguji hipotesis penelitian menggunakan analisis regresi linier berganda yaitu melihat pengaruh variabel independent (variabel bebas) terhadap variabel dependent (variabel terikat), dengan menggunakan persamaan matematis yaitu analisis regresi linier berganda dengan rumus :

$$
\mathrm{Y}=\mathrm{a}+\mathrm{blX} 1+\mathrm{b} 2 \mathrm{X} 2+\mathrm{b} 3 \mathrm{X} 3+\mathrm{e}
$$

Dimana :

$\begin{array}{ll}\mathrm{Y} & =\text { Kinerja } \\ \mathrm{a} & =\text { Konstanta } \\ \mathrm{X}_{1} & =\text { Disiplin } \\ \mathrm{X}_{2} & =\text { Motivasi } \\ \mathrm{X}_{3} & =\text { Fasilitas Kerja } \\ \mathrm{b} 1, \mathrm{~b} 2, \mathrm{~b} 3 & =\text { Koefisien Regresi } \\ \mathrm{e} & =\text { Standard error }\end{array}$

\section{Uji F (Pengujian Simultan)}

a. Jika $F_{h i t u n g}>F_{\text {tabel }}$ dan probabilitas (nilai signifikan) $<$ tingkat signifikansi $5 \% \quad(\alpha=$ 0,05), maka Ha diterima dan Ho ditolak berarti variable independent secara bersama-sama mempunyai pengaruh yang signifikan terhadap variabel dependent.

b. Jika $F_{\text {hitung }}<\mathrm{F}_{\text {tabel }}$ dan probabilitas (nilai signifikansi) $>$ tingkat signifikansi 5\% ( $\alpha=$ $0,05)$ maka HO diterima dan Ha ditolak berarti variabel independent secara bersamasama tidak mempunyai pengaruh yang signifikan terhadap variabel dependent.

Dimana nilai $\mathrm{F}_{\text {tabel }}$ ditentukan dengan mencari derajat bebasnya yaitu dfI $=\mathrm{k}-1$ dan df2=N-k, dimana $\mathrm{N}$ - jumlah sampel dan $\mathrm{k}=$ jumlah variabel.

\section{HASIL DAN PEMBAHASAN}

Statistik Deskriptif

Tabel 1. Statistik Deskriptif

\begin{tabular}{lllllllll}
\hline \multirow{2}{*}{ Variabel } & \multirow{2}{*}{ Instrumen } & \multicolumn{7}{c}{ Frekwensi (Persentase) } \\
\cline { 3 - 8 } & & $\mathbf{5}$ & $\mathbf{4}$ & $\mathbf{3}$ & $\mathbf{2}$ & $\mathbf{1}$ & Total \\
\hline Kinerja & 1. & KP1 & 34,1 & 65,9 & 0 & 0 & 0 & 100 \\
\hline
\end{tabular}




\begin{tabular}{lllllllll}
\hline Pegawai & 2. & KP2 & 37,8 & 62,2 & 0 & 0 & 0 & 100 \\
(Y) & 3. & KP3 & 18,3 & 68,3 & 13,4 & 0 & 0 & 100 \\
& 4. & KP4 & 43,9 & 56,1 & 0 & 0 & 0 & 100 \\
& 5. & KP5 & 48,8 & 48,8 & 2,4 & 0 & 0 & 100 \\
& 6. & KP6 & 31,7 & 68,3 & 0 & 0 & 0 & 100 \\
& 7. & KP7 & 45,1 & 47,6 & 7,3 & 0 & 0 & 100 \\
& 8. & KP8 & 34,1 & 63,4 & 2,5 & 0 & 0 & 100 \\
\hline \multirow{4}{*}{ Fasilitas } & 1. & FK1 & 30,5 & 67,1 & 2,4 & 0 & 0 & 100 \\
Kerja & 2. & FK2 & 34,1 & 62,2 & 3,7 & 0 & 0 & 100 \\
(X3) & 4. & FK3 & 18,3 & 64,6 & 15,9 & 1,2 & 0 & 100 \\
& 5. & FK5 & 39,3 & 68,3 & 12,2 & 1,2 & 0 & 100 \\
& 6. & FK6 & 15,9 & 76,0 & 0 & 0 & 0 & 100 \\
& 7. & FK7 & 32,9 & 57,3 & 7,3 & 2,5 & 0 & 100 \\
& 1. & FK8 & 50,0 & 50,0 & 0 & 0 & 0 & 100 \\
\hline
\end{tabular}

\section{Uji Kualitas Data}

\section{Validitas}

Tabel 2. Uji Validitas Variabel

\begin{tabular}{llllll}
\hline \multicolumn{1}{c}{ Variabel } & \multicolumn{2}{l}{ Instrumen } & r-hitung & r-tabel & Keterangan \\
& & & & & \\
\hline & 1) & FK1 & 0.647 & 0.217 & Valid \\
& 2) & FK2 & 0.714 & 0.217 & Valid \\
Fasilitas Kerja & 3) & FK3 & 0.649 & 0.217 & Valid \\
(X3) & FK4 & 0.754 & 0.217 & Valid \\
& 5) & FK5 & 0.703 & 0.217 & Valid \\
& 6) & FK6 & 0.714 & 0.217 & Valid \\
& 7) & FK7 & 0.620 & 0.217 & Valid \\
& 1) & FK8 & 0.709 & 0.217 & Valid \\
\hline \multirow{4}{*}{ Kinerja } & 1) & KP1 & 0.726 & 0.217 & Valid \\
Pegawai (Y) & 2) & KP2 & 0.710 & 0.217 & Valid \\
& 3) & KP3 & 0.579 & 0.217 & Valid \\
& 5) & KP4 & 0.707 & 0.217 & Valid \\
& 6) & KP6 & 0.728 & 0.217 & Valid \\
& 7) & KP7 & 0.641 & 0.217 & Valid \\
& 8) & KP8 & 0.647 & 0.217 & Valid \\
\hline
\end{tabular}

\section{Reliabilitas}

Tabel 3. Uji Reliabilitas Variabel

\begin{tabular}{lccc}
\hline Variabel & $\begin{array}{c}\text { Cronbach's } \\
\text { Alpha }\end{array}$ & $\begin{array}{c}\text { Batas } \\
\text { Reliabilitas }\end{array}$ & Keterangan \\
\hline Fasilitas Kerja (X3) & 0.768 & 0.6 & Reliabel \\
Kinerja Pegawai (Y) & 0.767 & 0.6 & $\begin{array}{l}\text { Reliabel } \\
\text { Reliabel } \\
\end{array}$ \\
& & & Reliabel \\
\hline
\end{tabular}

Dari data tabel di atas dapat dilihat bahwa hasil perhitungan uji reliabilitas menunjukkan alpha cronbach's pada masing-masing kolom variabel tersebut lebih besar dari 0,6 (batas reliabilitas) maka dapat dinyatakan instrumen tersebut reliabel. 


\section{Pengujian Hipotesis}

\section{Pengujian Hipotesis dengan Uji t}

Variabel fasilitas kerja memiliki nilai $p$-value (pada kolom Sig.) 0,016 $<0,05$ artinya signifikan, sedangkan $\mathrm{t}$ hitung 2,458 > dari t tabel 1,991 artinya signifikan. Hal ini berarti bahwa fasilitas kerja berpengaruh terhadap kinerja pegawai.

\section{Analisis Koefisien Determinasi $\left(\boldsymbol{R}^{2}\right)$}

Tabel 4. Model Summary

\begin{tabular}{ll|r|r|r} 
Mod & R & R Square & \multicolumn{1}{c}{$\begin{array}{c}\text { Adjusted R } \\
\text { Square }\end{array}$} & $\begin{array}{l}\text { Std. Error of } \\
\text { the Estimate }\end{array}$ \\
\hline 1 & $.657^{\mathrm{a}}$ & .432 & .410 & 2.186 \\
\hline
\end{tabular}

a. Predictors: (Constant), FasilitasKerja, Motivasi, Disiplin

Hasil olahan pada tabel di atas terlihat nilai koefisien determinasi $\left(R^{2}\right)$ yang sudah disesuaikan (Adjusted $R$ Square) sebesar 0,410. Artinya 41,0\% variabel dependen (kinerja pegawai) dipengaruhi atau dijelaskan oleh variabel independen yaitu fasilitas kerja, dan sisanya sebesar 59,0\% (100\% - 41,0\%) dipengaruhi atau dijelaskan oleh variabel lain di luar variabel yang digunakan dalam penelitian ini.

\section{Hasil Persamaan Regresi}

\begin{tabular}{|c|c|c|c|c|c|c|}
\hline \multirow[b]{3}{*}{ Model } & \multicolumn{6}{|c|}{ Tabel 5. Coefficients ${ }^{\mathrm{a}}$} \\
\hline & & \multicolumn{2}{|c|}{$\begin{array}{l}\text { Unstandardized } \\
\text { Coefficients }\end{array}$} & \multirow{2}{*}{$\begin{array}{c}\text { Standardized } \\
\text { Coefficients } \\
\text { Beta } \\
\end{array}$} & \multirow[b]{2}{*}{$\mathrm{t}$} & \multirow[b]{2}{*}{ Sig. } \\
\hline & & $\mathrm{B}$ & Std. Error & & & \\
\hline \multirow[t]{2}{*}{1} & (Constant) & 9.095 & 3.412 & & 2.666 & .009 \\
\hline & FasilitasKerja & .279 & .113 & .300 & 2.458 & .029 \\
\hline
\end{tabular}

Persamaan regresi yang telah dirumuskan dilakukan pengolahan data sehingga didapat persamaan akhir yaitu :

$$
Y=9,095+0,223 X_{1}+0,253 X_{2}+0,279 X_{3}
$$

Pada model regresi ini, nilai konstanta yang tercantum sebesar 9,095 dapat diartikan jika variabel bebas dalam model diasumsikan sama dengan nol atau variabel bebas dalam hal ini disiplin, motivasi dan fasilitas kerja diterapkan, maka kinerja pegawai akan mengalami kenaika sebesar 9,095 satuan. Nilai besaran koefisien regresi $\beta_{3}$ sebesar 0,279 pada penelitian ini dapat diartikan bahwa variabel fasilitas kerja (X3) berpengaruh positif terhadap kinerja pegawai $(Y)$. Hal ini menunjukkan bahwa ketika variabel fasilitas kerja terpenuhi, maka kinerja pegawai akan naik/baik.

\section{Pengaruh Fasilitas Kerja Terhadap Kinerja Pegawai}

Secara parsial hasil penelitian ini menunjukan bahwa fasilitas kerja berpengaruh positif dan signifikan terhadap kinerja pegawai di Perusahaan Daerah Pasar Kota Medan. Pengaruh positif menunjukkan bahwa pengaruh fasilitas kerja adalah searah dengan kinerja pegawai atau dengan kata lain adanya fasilitas kerja yang baik akan berpengaruh terhadap kinerja 
pegawai yang baik/tinggi, demikian sebaliknya bila fasilitas kerja yang baik tersebut tidak terpenuhi, maka kinerja pegawai akan rendah/buruk. Pengaruh signifikan menunjukkan bahwa fasilitas kerja mempunyai peranan yang penting dalam meningkatkan kinerja pegawai di Perusahaan Daerah Pasar Kota Medan.

\section{KESIMPULAN}

Penelitian ini bertujuan untuk melihat pengaruh disiplin, motivasi dan fasilitas kerja terhadap kinerja pegawai baik secara simultan maupun parsial. Hasil penelitian ini memberikan kesimpulan fasilitas kerja secara parsial berpengaruh terhadap kinerja pegawai di Perusahaan Daerah Pasar Kota Medan. Berdasarkan uji t Variabel fasilitas kerja memiliki nilai p-value (pada kolom Sig.) 0,016 <0,05 artinya signifikan, sedangkan t hitung 2,458 > dari t tabel 1,991 artinya signifikan. Hal ini berarti bahwa fasilitas kerja berpengaruh terhadap kinerja pegawai.

\section{SARAN}

Berdasarkan kesimpulan dalam penelitian ini, maka dapat dikemukakan beberapa sara agar perusahaan Daerah Pasar Kota Medan sebaiknya memperhatikan dan meningkatkan disiplin terhadap pegawai untuk meningkatkan motivasi bekerja dengan fasilitas kerja yang disediakan Perusahaan sehingga kinerja pegawai juga akan dapat meningkat untuk mencapai tujuannya. Penelitian ini perlu dikembangkan lebih jauh lagi, untuk mendapatkan hasil empiris yang lebih kuat yaitu dengan menambah variabel lain yang mempengaruhi kinerja pegawai.

\section{DAFTAR PUSTAKA}

Cascio, Wayne F. 2006. Managing Human Resources, Productivity, Quality of Work Life, Profits, edition, New York, Mc Graw Hill

Ridwan. 2007. Skala Pengukuran Variabel - Variabel Bandung: Alfabeta

Robbins, P. Stephen, Coulter Mary Alih bahasa oleh Benyamin. 2009. Manajemen, Edisi keenam, Jilid 2. Jakarta: PT. Indeks

Rivai Veithzal. 2009. Manajemen Sumber Daya Manusia untuk perusahaan dari Teori ke Praktik. Jakarta: Raja Grafindo Persada

Bougie, Roger dan Uma Sekaran. 2010. Research Methods For Business, Fifth Edition. John Wiley and Sons Ltd.

Wibowo. 2007. Manajemen Kinerja, Cetakan Pertama. Jakarta: Raja Grafindo Persada

Yeltsin Apprioke Thomas. 2010. Pengaruh fasilitas kerja terhadap kinerja PNS di Kantor Perusahaan Daerah Pasar Kota Medan 
